\title{
JORNAL DO ALMOÇO - UMA ANÁLISE SOBRE IDENTIDADE E DIFERENÇA CULTURAL
}


JORNAL DO ALMOÇO - UMA ANÁLISE SOBRE IDENTIDADE E DIFERENÇA CULTURAL

Resumo:

Este trabalho busca elementos para uma hipótese de identidade cultural gaúcha através da análise das práticas produtivas do Jornal do Almoço, da RBS TV. Trata-se de uma análise sob amparo dos Estudos Culturais, cujo foco se dirige a edições do telejornal, selecionadas por conveniência, destacando as matérias e os comentários dos apresentadores. Como resultado se verifica os registros de notabilidade da cultura gaúcha, na produção, fatos e cenas do telejornal.

Palavras chave: Telejornalismo; Identidade cultural; Gaúcho

\title{
JORNAL DO ALMOÇO - AN ANALYSIS ABOUT IDENTITY AND CULTURAL DIFERENCE
}

\begin{abstract}
:
This paper searches elements to a hypothesis of cultural identity gaúcha (name given to people living in Rio Grande do Sul, Brazil) through the analysis of the production practices of Jornal do Almoço, of RBS TV. It is an analysis in support of the Cultural Studies, whose focus is directed to editions of the TV newscast, selected for convenience, highlighting the materials and the comments of the presenters. As a result it is checked the records of nobility of gaúcha culture, in production, facts and scenes of this TV newscast.
\end{abstract}

Keywords: TV Newscast; Cultural identity; Gaúcho

JORNAL DO ALMOÇO - UN ANÁLISIS SOBRE IDENTIDAD Y DIFERENCIA CULTURAL

Resumo:

Este trabajo busca elementos para una hipótesis de identidad cultural gaucha por medio del análisis de las prácticas productivas del Jornal do Almoço, de la RBS TV. Tratase de un análisis de acuerdo con los estudios culturales, cuya centralidad se dirige a las ediciones del tele periodismo, seleccionadas por conveniencia, destacando las materias y los comentarios de los presentadores. Como resultado verificas los registros de notabilidad de la cultura gaucha, en la producción, factos y escenas del tele periodismo.

Palabras Clave: Tele periodismo; Identidad cultural; Gaucho 


\section{INTRODUÇÃO}

A delimitação do estudo encontra-se no estudo de caso de edições de diferentes dias, do telejornal da mais antiga afiliada da Rede Globo, a Rede Brasil Sul de Televisão (RBS TV), Jornal do Almoço, que se utilizou de representações da identidade regional no contexto da apresentação. Com esse objetivo, o desenvolvimento desta pesquisa guarda sua referência inicial nas questões identitárias construídas, mantidas e extremamente popularizadas - em termos de ampla divulgação na esfera social e midiática - pelo Movimento Tradicionalista Gaúcho, o MTG.

A questão problema ocupou-se em identificar como se dão os processos de identidade com a cultura gaúcha nas notícias, e no que se refere aos acontecimentos jornalísticos e fatos registrados pelo telejornal do almoço "JA", tendo-se por parâmetro o cânone identitário criado, sustentado e popularizado pelo MTG.

O corpus foi formado por seis telejornais, e o período de coleta ficou delimitado em três meses (junho, julho e agosto). Para fins ilustrativos da metodologia e da aplicação das categorias de análise, neste artigo se apresenta apenas uma edição do telejornal veiculado no dia nove de julho.

Segundo o relatório da ANDI, vale lembrar que, nas sociedades contemporâneas, o provimento de informações sobre o mundo é função de sistemas específicos, dentre os quais aqueles que constituem o jornalismo. Partindo da ideia de que o jornalismo tornou-se estruturante e intermediador das relações nas sociedades modernas, por meio de uma representação do espaço público e, desta forma, indispensável aos cidadãos para acesso à informação, o relatório adota o entendimento de Giddens sobre os sistemas que operam na sociedade, dentre eles, o jornalismo como promotor de reflexão.

Assim, o jornalismo é um sistema perito que exige, da parte de seus clientes ou consumidores, a confiança em sua competência específica, pois sem credibilidade, as informações providas pela mídia perdem relevância. Essa confiança não se ampara em experiências anteriores ou de outras pessoas. Em se tratando de jornalismo, na maior parte das vezes, a possibilidade de replicação de experiências pregressas não existe. A confiança em um determinado noticiário não se dá pela vivência, mas graças a noticiários concorrentes, que apresentam conteúdo similar.

Diante de tal análise, podemos dizer que a crença depositada na cobertura jornalística pelo consumidor de informações pode ser dividida em três elementos. Primeiro, na escolha acertada, entre a infinidade de eventos que ocorrem a cada dia, de quais mereceriam ser alçados à condição de "fatos jornalísticos". Depois, dentre os eventos eleitos, na correta formatação dos elementos a serem noticiados, considerados limites de tempo e de espaço 
(framing). Por fim, a confiança na veracidade - conceito que varia conforme o receptor da informação - dos fatos relatados. A imprensa possui, assim, uma espécie de monopólio quanto à seleção e configuração das notícias, que acabam sendo apresentadas como "a" realidade. (ANDI, 2007, pág. 50).

Essa confiança ampara-se em experiências anteriores ou de outras pessoas, que apostaram na divulgação de determinada noticia, a qual chegou ao destino desejado.

A confiança em um determinado noticiário não se dá pela vivência, mas graças à comparação com noticiários concorrentes, que apresentem conteúdo similar.

\section{OS VALORES-NOTÍCIA}

No campo do jornalismo, os valores-notícia estão diretamente ligados às rotinas produtivas. Por sua formação, o jornalista tem uma visão diferente das demais pessoas, desta forma, ele é capaz de fazer uma seleção pessoal sobre os fatos que considera mais importante. Há dois tipos de valores-notícia: de seleção ou construção. O primeiro está ligado aos critérios utilizados pelos jornalistas na hora de fazer a seleção dos acontecimentos, ou seja, o que será transformado em notícia e o que não passará de um fato sem divulgação na mídia. Já o segundo, diz respeito a tudo que será levado em conta na hora de se construir uma notícia.

A primeira definição do que são valores-notícia foi feita pelo italiano Mauro Wolf. Tranquina 2005, página 35) complementa, afirmando que a mídia que noticia os fatos que ocorrem no dia-a-dia destina um amplo espaço para alguns assuntos e questões, que por vez são do interesse das grandes massas.

Traquina trabalha com outros critérios que são importantes para justificar os valoresnotícia: a notoriedade, o prestígio e a fama dos envolvidos são quesitos fundamentais para classificar os acontecimentos como notícia. Além disso, a proximidade, já que a distância geográfica serve como forma de avaliação para a seleção das notícias; a relevância, que serve como forma de classificar os assuntos que terão impacto sobre a vida das pessoas; o tempo, responsável por noticiar fatos atuais ou referir fatos que já aconteceram; a notabilidade, responsável por tornar notícia acontecimentos que envolvam muitas pessoas, ou então, fatos inusitados ou insólitos; o inesperado, que rompe com as expectativas da comunidade jornalística; o conflito ou a controvérsia, representado pela violência física ou simbólica; a infração, ou seja, a quebra de regras, o crime como notícia.

Nos valores-notícia de seleção, existem alguns critérios contextuais, que fazem parte do processo de produção das notícias. Faz-se, então, uma breve 
apresentação destes critérios. Começa-se com a questão da disponibilidade, ou seja, a facilidade de cobertura em certos acontecimentos. Passa-se, a seguir, para a questão do equilíbrio, onde os fatos deixam de ser notícia na atualidade por terem sido no passado. Chega-se na visualidade, onde a imagem é decisiva para a seleção ou não da notícia. Ressalta-se, também, a questão da concorrência, que existe de forma direta e indireta entre as empresas jornalísticas. Por último, chama-se atenção para a questão do dia noticioso, uma vez que existem dias com muitos acontecimentos com valor-notícia e outros sem qualquer acontecimento que possa ser considerado um valor-notícia.

Os valores-notícia de construção podem ser entendidos pela seleção de todos os acontecimentos que de alguma forma se tornam relevantes para a criação de uma notícia. Pode-se citar como exemplos: a simplificação (uma notícia fácil de ser entendida toma o lugar de uma muito complexa); a amplificação (quanto mais forte for uma notícia, mais ela será notada); a relevância (a notícia só será notada se ela der sentidos aos acontecimentos); a personalização (valorização das pessoas envolvidas) e a dramatização, que é o reforço do lado emocional (TRAQUINA 2005). Segundo o autor, entende-se por notícia todo aquele acontecimento que ocorre quando tudo é inesperado, ou seja, é algo inusitado, que envolve várias pessoas e que de alguma forma possui ligações com os diversos critérios de noticiabilidade abordados nos parágrafos anteriores.

\section{IDENTIDADE E DIFERENÇA}

Em seu artigo Identidade e diferença: uma introdução teórica e conceitual, Kathryn Woodward (2000) aponta que a representação atua simbolicamente para classificar o mundo e as relações no seu interior. Para ela, as identidades culturais precisam de conceitualização, a fim de compreender como funcionam e dividi-las em diferentes dimensões.

A identidade é, na verdade, relacional, e a diferença são estabelecidas por uma marcação simbólica relativamente a outras identidades (na afirmação das identidades nacionais, por exemplo, os sistemas representacionais que marcam a diferença podem incluir

um uniforme, uma bandeira). No caso da identidade regional, como a que se analisam, as marcas estão na fala com sotaque, na vestimenta, em hábitos e atitudes e até mesmo, na produção de conteúdo. O conceito de identidade pode estar ligado com as representações.

Por que estamos examinando a identidade e a diferença? Ao examinar sistemas de representação, é necessário analisar a relação entre cultura e significado (Hall, 1997). Só podemos compreender os significados envolvidos nesses sistemas se tivermos 
alguma ideia sobre as quais posições-de-sujeitos eles produzem e como nós, como sujeitos, podemos ser posicionados em seu interior. Aqui, estaremos tratando de outro momento do "circuito da cultura": aquele em que o foco se desloca dos sistemas de representação para as identidades produzidas por aqueles sistemas (WOODWARD, 2000, p.16).

As identidades são fabricadas por meio da marcação da diferença. Essa marcação ocorre tanto por símbolos quanto por formas de exclusão social. A identidade, pois, não é o oposto da diferença: a identidade depende da diferença. Nas relações sociais, essas formas de diferença - a simbólica e a social são estabelecidas, ao menos em parte, por meio de sistema classificatório, que aplicam um princípio de diferença a uma população de tal forma que seja capaz de dividi-la em ao menos dois grupos opostos.

Cada cultura tem suas próprias e distintas formas de classificar o mundo. A cultura propicia sentidos ao mundo social, assim, podem-se construir significados. O sistema partilhado de significação é, na verdade, o que se entende por cultura:

A cultura, no sentido dos valores públicos, padronizados, de uma comunidade, serve de intermediação para a experiência de indivíduos. Ela fornece, antecipadamente, algumas categorias básicas, um padrão positivo, pelo qual as ideias e os valores são higienicamente ordenados. E, sobretudo, ela tem autoridade, uma vez que cada um é induzido a concordar por causa da concordância dos outros (KELLNER apud WOODWARD, 2000, p.42).

Em ensaio justamente intitulado "A produção social da identidade e diferença”, Tomas Tadeu Silva (2000) explica que identidade e diferença estão em estreita conexão com as relações de poder, por isso, as identidades nacionais podem assumir um teor manipulador, predominantemente ideológico e, por vezes, segregacionista: "O poder de definir a identidade e de marcar a diferença não pode ser separado das relações mais amplas de poder. A identidade e a diferença não são, nunca, inocentes" (SILVA, 2000, p. 81).

A identidade e a diferença se traduzem em declarações sobre quem pertence e não pertence. Afirmar a identidade significa demarcar fronteiras, fazer distinções sobre o que fica dentro ou fora. Essas demarcações afirmam, ao mesmo tempo, relações de poder.

Já sabemos que a identidade e a diferença estão estreitamente interligadas a sistemas de significação. A identidade é um significado - cultural e socialmente atribuído. A teoria cultural recentemente expressa essa mesma ideia por meio do conceito de representação. Para a teoria cultural contemporânea, a iden- 
tidade e a diferença estão estreitamente associadas a sistemas de representação (SILVA, 2000, p. 89).

É por meio das representações que, por assim dizer, a identidade e diferença passam a existir. Stuart Hall, em seu artigo Quem precisa de identidade? aponta o caráter da reflexão sobre identidade cultural. Para ele, as identidades culturais podem ser vistas, em primeiro lugar, em concepção essencialista, que recupera o passado de uma comunidade para a formulação da identidade, ou seja, em termos de cultura partilhada. A segunda maneira de pensar identidade cultural que ele indica parte do reconhecimento de que se há pontos de similaridades que produzem as identificações entre os sujeitos que constroem uma identidade, esta também é produzida através dos pontos críticos de diferença.

Na linguagem do senso comum a identificação é construída a partir do reconhecimento de alguma origem comum, ou de características que são partilhadas com os outros grupos ou pessoas, ou ainda a partir de um mesmo ideal. É em cima dessa função que ocorre o natural fechamento que forma da solidariedade e da fidelidade do grupo em questão (HALL, 2000, p.106).

Como um processo nunca é completo, de acordo com Hall (2000), a abordagem discursiva vê a identificação. Trata-se de um processo de articulação, uma suturação, uma sobre determinação que definem a identificação. Essa concepção aceita que as identidades não são unificadas; que elas são, na modernidade tardia, cada vez mais fragmentada e fraturada; que não são singulares, mas multiplamente construídas ao longo de discurso, práticas e posições que podem se cruzar ou ser antagônicas.

As identidades têm a ver, entretanto, com a questão da utilização dos recursos da história, da linguagem e da cultura para a produção não daquilo que nós somos, mas no que nos tornamos. Castells (2006, p. 22-23) entende identidade como "o processo de construção com base em um atributo cultural, o ainda, um conjunto de atributos culturais inter-relacionados, o(s) qual (is) prevalece $(m)$ sobre outras fontes significáveis". E, significado, como "a identificação simbólica, por parte de um ator social, de finalidade da ação praticada por tal ator".

Castells (2006, p. 23) afirma que, de um ponto de vista sociológico, "toda e qualquer identidade é construída", e também que:

a construção de identidades vale-se da matéria prima fornecida pela história, geografia, biologia, instituições produtivas e reprodutivas, pela memória coletiva e por fantasias pessoais, pelos aparatos de poder e revelações de cunho religioso. Porém, todos esses materiais são processados pelos indivíduos, grupos sociais e sociedades, que reorganizam seu significado em 
função de tendências sociais e projetos culturais enraizados em sua estrutura social, bem como em sua visão de espaço/ tempo (CASTELLS, 2006, p. 23).

Segundo Laraia (1986, p. 63-64), Geertz afirma que a cultura não se define por "um complexo de comportamentos concretos, mas por um conjunto de mecanismos de controle, planos, receitas; regras, instruções (que os técnicos de computador chamam programa) para governar o comportamento". Metaforicamente, "todos os homens são geneticamente aptos a receber um programa, e este é que chamamos cultura". Mais à frente, exemplifica dizendo: "uma criança está apta ao nascer a ser socializada em qualquer cultura existente. Este amplitude de possibilidades, entre tanto, será limitada pelo contexto real e específico onde fato ela nascer". Já para Schneider, ainda segundo Laraia (1986, p. 65), "cultura é um conjunto de símbolos e significados. Compreender categorias ou unidades e regras sobre relações e modo de comportamento".

Quando estabelecemos relações entre as noções de identidade cultura, podemos observar que, segundo Ronsini (2007), tais noções apresentam como semelhança os fatos de ambos serem contribuições simbólicas, ambas falarem de um pertencimento em relações a um referencial, e de ambas estarem imbricadas com a vida cotidiana e com a estrutura social. A mesma autora afirma que podemos fazer a seguinte relação entre essas noções: a cultura organiza identidades e identidade organizam os significados. Dessa forma, ela define identidade como:

os processos simbólicos de pertencimento em relação a referentes a variados como cultura, nação, classe, grupo ético ou gênero. Tais referentes dizem respeito a aspectos objetivos como posição do sujeito na estrutura social e a aspectos subjetivos ou descritivos que os atores utilizam para incluíremse/excluírem-se (RONSINI apud FLORES, 2011, p. 24).

A proposição de Silva (2000) considera que as identidades se estabelecem na diferença. Explica ele que identidade parece ser aquilo que se é uma afirmação, uma característica independente. Sou gaúcho, sou homem, sou muIher; por exemplo. Já a diferença, em oposição, igualmente aparece como uma característica independente: aquilo que o outro é algo que é visto no outro e que remete, por oposição, a si mesmo. Dessa forma, identidade e diferença mostram-se inseparáveis. Mas aqui, busca-se tratar da caracterização da identidade da cultura gaúcha.

\section{IDENTIDADE CULTURAL GAÚCHA}

A relação entre a mídia do Rio Grande do Sul e a identidade cultural - no caso específico a gaúcha - intensifica-se nos anos 80 , num contexto de forte 
atuação de movimentos culturais de fixação da identidade cultural gaúcha e de expansão dessa indústria cultural. Nesse período, a indústria cultural gaúcha despertou para um fenômeno que acontecia no Estado desde a metade do século, o renascimento do gauchismo, através dos movimentos Tradicionalista ${ }^{1}$ e Nativista. Retardatária ao processo, com exceção do rádio que registrava programas desde os anos 50, a indústria cultural passou a dar espaço a esses movimentos, encontrando aí um filão de mercado e contribuindo para sua potencialização. Conforme Jacks (1998), o rádio foi o primeiro a dar esse espaço, na cobertura de festivais musicais. Surgiram revistas e jornais temáticos e editoras especializadas, houve desenvolvimento de uma indústria fonográfica ligada aos festivais nativistas e o cinema veio com algumas produções, embora fosse nos anos 90 que esse último respondeu a esses movimentos. A televisão, por meio da RBS e da Televisão Educativa (TVE), começou a abordar a temática em especiais musicais e jornalísticos.

A identidade cultural gaúcha foi consolidada na metade do século passado. Sua emergência é histórica, localizada em um ponto específico no tempo. Uma das formas pelas quais as identidades estabelecem suas reivindicações é por meio do apelo a antecedentes históricos, buscando-as no passado, mas, quando o fazem, podem estar produzindo novas identidades (Woodward, 2000), tendo a memória como suporte. Na constituição da identidade gaúcha, os antecedentes históricos são encontrados no período de demarcação das fronteiras meridionais do Brasil - consequente surgimento do Estado na Revolução Farroupilha. Corso (2002) explica que a Revolução Farroupilha deixou resíduos de uma nação que nunca existiu, mas vive na imaginação dos gaúchos. Segundo Corso (2002), como nunca foi construído, é projetada como algo meIhor do que o Brasil real, "uma nação de liberdade e fraternidade" (p. 8).

A correlação entre cultura regional e indivíduos forma a identidade. Fatores históricos, geográficos, econômicos e sociais influenciam nas especificidades culturais dos habitantes de uma região, num processo bastante dinâmico. Para Jacks (1999), cultura regional "é um dos fatores de determinação de prá10 Tradicionalismo é inaugurado por volta de 1940, com a criação dos Centros de Tradição Gaúcha (CTGs), resultado de agremiações cívicas anteriores que buscavam apoiar a República através do patriotismo e o culto às tradições nacionais e regionais. Foi um movimento de jovens das classes média e alta, que moravam em Porto Alegre, mas tinham origem na Campanha gaúcha, como uma reação à entrada de produtos da indústria cultural norte-americana, principalmente do cinema. O Nativismo foi uma reação ao Tradicionalismo. Surgiu nos anos 70, desencadeado pelos festivais de música, causando efervescência na produção cultural gaúcha, tornando-se ainda, posteriormente, de costumes e de consumo. A população de classe média, urbana, passou a adotar hábitos tradicionais, como o chimarrão, a bombacha e expressões típicas do linguajar da Campanha. O movimento objetivava renovar os padrões estéticos. Tinha caráter de contestação social e política, refletido nas letras das canções. Inicialmente, os dois movimentos entraram em conflito, mas chegaram a um momento de assimilação mútua. O Nativismo abriu espaços para as manifestações culturais nos meios de comunicação, criando mercado promissor para esse segmento e ampliando as dimensões do movimento (Jacks, 1998). 
ticas culturais que diferenciam determinado grupo, fornecendo-lhes uma identidade própria" (p.66). Uma cultura regional envolve subculturas, no interior da qual uma pode ser hegemônica. A cultura regional é também uma subcultura em relação à cultura geral. O Rio Grande do Sul, conforme Jacks comporta subculturas provenientes das correntes migratórias açoriana, italiana e alemã, mais representativas, e polonesa, russa, holandesa, japonesa, judia e negra; e uma subcultura anterior, a gaúcha. Essa é que fornece a simbologia usada para firmar a identidade regional perante as demais regiões do país. Essa seria a subcultura hegemônica, que serviu de representação também para os demais grupos étnicos do Estado. Mas a cultura gaúcha fixada no auge da pecuária extensiva e consolidada pela historiografia e literatura oficiais seria representativa, porque há muito deixou de corresponder à realidade concreta e é só vivida culturalmente, aponta Jacks (199). E, hoje, os principais locais de vivência simbólica dessa cultura regional são os CTGs, o Estado, a escola, a sociedade civil e os meios de comunicação de massa.

Se no passado literatura e historiografia contribuíram para a constituição da identidade cultural gaúcha, nas duas últimas décadas, dada a centralidade da mídia, especialmente os meios de comunicação têm se encarregaram desse papel. No Rio Grande do Sul, o destaque é da RBS que, pela sua força e alcance, tem papel fundamental no processo. Seja em rádio, TV ou jornal, a programação jornalística e de ficção e a propaganda institucional do grupo evidenciam uma estratégia de inserção regional com valorização da cultura local. Assim, neste estudo de caso, busca-se como é dada a visibilidade a este tema no Jornal do Almoço, veiculado pela rede.

\section{O TRADICIONALISMO NO TELEJORNAL DO ALMOÇO}

Seguindo uma estratégia que é de todo grupo RBS, os espaços para a temática da cultura regional, que age na construção da identidade cultural gaúcha, são sempre pauta de diferentes edições. Esse comportamento do jornal é observado em diferentes formas: na destinação de espaços específicos para o tema (notas, reportagens ou entrevistas), cobertura de eventos especiais e no tratamento dado a algumas notícias do dia a dia nos diferentes blocos.

Em relação à cobertura de eventos especiais, a maior ocorrência acontece em setembro, durante as comemorações Semana Farroupilha. Nesse período, rotineiramente o telejornal produz reportagens veiculadas ao longo da semana e cobre eventos pontuais que acontecem pelo Estado nesses dias, como acampamentos, cavalgadas, mateadas e desfiles.

Outro caso observado de espaço para a temática da cultura gaúcha parece ser o mais interessante para estudo, é quando não há uma agenda e nem data especial, sendo este o objeto desse artigo. Para ilustrá-lo, podemos exemplificar a edição de nove de julho de 2011, no primeiro bloco viu-se na edição feita em Santa Maria, informações bem regionais e da cidade, como: Segundo dia 
de Feira do Cooperativismo, conflito entre pedestres e motoristas no trânsito e a informação da corrida de carrinhos de lomba na cidade.

Já nos blocos estaduais, apresentados de Porto Alegre, um especialista mostrou as principais maneiras de preparar o chimarrão. O que é importante deixar claro é que essas coberturas extrapolam a obediência ao critério de noticiabilidade da proximidade, ou seja, a eleição de fatos que evidenciam assuntos e personalidades locais, próximas ao local que o produz. A ação do telejornal na construção da identidade cultural gaúcha já está na pauta (acontecimento). O enfoque dado a elas e a narrativa empregada (construção em si da notícia) trazem elementos da cultura regional. Esses elementos funcionam como estratégias discursivas que mobilizam a memória do receptor, que os reconhece nesse discurso.

\section{CONSIDERAÇÕES}

Nessa análise de caráter ilustrativo, foi possível verificar que o telejornal se ocupa da formação da identidade cultural gaúcha quando faz circular (cria) acontecimentos que se relacionam com a cultura regional. E que procura (re) criar uma identidade cultural que remete a sentidos positivos sobre o ser gaúcho. As reportagens analisadas são exemplos de como o jornalismo realiza a construção da identidade, utilizando as técnicas de seleção de assuntos e de fontes e uma forma de narrativa para construir "um mundo possível", travestido de relato fiel à realidade objetiva dessa notícia. E demonstram que existe uma relação da indústria cultural - em questão a RBS - com a cultura regional no Rio Grande do Sul que já caracteriza a primeira.

Acredita-se que essa relação tem sido positiva para o grupo, que tem adotado essa fórmula há bastante tempo, tornando-se um local de vivência da cultura regional e, consequentemente, de resistência à homogeneização cultural, ao menos uma resistência a uma cultura global. Num mundo de identidades híbridas, plurais, acredita-se que a RBSTV tem conseguido seduzir telespectadores, assujeitá-los quando propõe um discurso que foge da tendência à homogeneização e valoriza o regional (local x global), especialmente da forma como o faz, construindo uma identidade cultural gaúcha positiva, contribuindo para a constituição do imaginário social de valorização do gaúcho em relação ao outro.

\section{REFERÊNCIAS}

ANDI. Agência de notícias de direitos da infância - Mídia e Políticas públicas de comunicação. Brasília: 2007. Disponível em: http://www.andi.org.br/_pdfs/midia_ppc.pdf CASTELLS, M. O poder da identidade. 5. ed. São Paulo: Paz e Terra, 2006. CORSO, Mário. O sonho Piratini e a identidade gaúcha. In: Zero Hora/Caderno de Cultura. Porto Alegre, n. 13.547, 2002, p. 8. 
DIAS, Cláudia. Estudo de caso: idéias importantes e referências. 2000. Disponível em: http:// www.reocities.com/claudiaad/case_study.pdf. Acesso em: 23 de março de 2011.

GIDDENS, Anthony. The consequences of modernity. Stanford: Stanford University Press, 1990.

GIROUX, H. A. Praticando Estudos Culturais nas faculdades de educação. In: SILVA, T.T. (org.). Alienígenas na sala de aula: uma introdução aos estudos culturais em educação. Petrópolis, RJ: Vozes, 1995.

HALL, Stuart. Quem precisa de identidade?In: SILVA, Tomás Tadeu da. (org.) Identidade e diferença: a perspectiva dos estudos culturais. Petrópolis: Vozes, 2000. p. 103-133. JACKS, Nilda. Mídia Nativa: Indústria Cultural e Cultura Regional. Porto Alegre: UFRGS, 1998. . Querência: Cultura Regional como Mediação Simbólica. Porto Alegre: UFRGS, 1999. LARAIA,R.B. Cultura: um conceito antropológico. Rio de Janeiro: Jorge Zahar, 1986. NELSON, C.; TREICHLER, P.A.; GROSSBERG, L. Estudos Culturais: uma introdução. In: SILVA, T.T. (org.). Alienígenas na sala de aula: uma introdução aos estudos culturais em educação. Petrópolis, RJ: Vozes, 1995.

SANTAELLA, Lúcia. O projeto de pesquisa e seus passos. In: Santaella, Lúcia. Comunicação e Pesquisa: projetos para mestrado e doutorado. São Paulo: Hacker, 2001.

SILVA, Tomaz Tadeu da. A produção social da identidade e da diferença. In SILVA, Tomás Tadeu da. (org.) Identidade e diferença: a perspectiva dos estudos culturais. Petrópolis: Vozes, 2000. p. 73-102

SILVA, T.T. Documentos de Identidade: uma introdução às teorias do currículo. Belo Horizonte: Autêntica, 1999.

TRAQUINA, Nelson. Teorias do jornalismo: a tribo jornalística; uma comunidade interpretativa transnacional. Florianópolis: Insular, 2005.

WOODWARD, Kathryn. Identidade e diferença: uma introdução teórica e conceitual In: SILVA, Tomás Tadeu da. (org.) Identidade e diferença: a perspectiva dos estudos culturais. Petrópolis: Vozes, 2000. p. 7-72 


\section{Ana Luiza Coiro Moraes}

Professora Visitante do Programa de Pós-Graduação em Comunicação da Universidade Federal de Santa Maria (UFSM). Doutorado em Comunicação Social (PUCRS); Mestrado em Comunicação Social (PUCRS); Especialização em Teoria do Jornalismo e Comunicação de Massa (PUCRS); Licenciatura em Letras (UFRGS). Área de pesquisa: Comunicação, com ênfase em Estudos Culturais, atuando principalmente com os seguintes temas: cultura, consumo, personagens e protagonismo midiáticos e epistemologia dos Estudos Culturais.

\section{Evandro Freitas}

Estudante de Graduação do Curso de Comunicação Social Jornalismo da Unifra. 